\title{
The impact of food and economic crises on diet and nutrition
}

The conventional view is that inelastic demand makes consumption of staple foods resilient to major price and income shocks. We explore the dietary and nutritional implications of a major shock in Bulgaria in the mid-1990s with data from before, during and after the shock. While demand for foodstuffs may remain relatively unchanging in environments characterised by stable food prices and incomes, economic crises and significant price spikes appeared to induce dramatic changes in price and income demand elasticities. We therefore suggest the use of caution in basing policy prescriptions on randomly available pre-crisis simulations.

\section{Introduction}

Given the well-established fact that both the calorie intake and the composition of the diet have important implications for health, mortality, fertility and economic productivity, it is not surprising that one of the most high profile areas of economic research is the impact of changing prices and incomes on diet and nutrition. While research in this area has traditionally focused on hunger alleviation and degenerative health in the process of industrialisation and development, occasional food crises and poverty increases as part of structural reforms in the 1980s and 1990s turned the attention of experts towards the potentially detrimental effect of fluctuating food prices and incomes on diet and nutrition. Most recently- in 2008 and later- the incidence of doubling staple prices lead to a new spike in studies on the subject.

Although rigorous academic research has attempted to keep up with this policy concern by providing estimates of the nutritional and other consequences of price and income shocks, it has failed to reach unambiguous conclusions. The prolific 1990s literature on the impact of economic shocks on nutrition and health does not agree on whether relatively 
poorer or relatively more affluent households are among the largest victims of economic shocks (Stillman, 2006; Frankenberg, Thomas and Beegle, 1999). At the same time, the more recent (and rapidly expanding in the post-2008 era) literature on the effect of food price shocks has not found an unambiguous answer to the question of how inelastic -and hence resilient to significant fluctuations in prices - the demand for staple food is and what implications this may have for nutrition.

For instance, in their analysis of the food price inflation effect of the 1994 CFA devaluation, Diagana, Akindès, Savadogo, Reardon and Staatz (1999) find that staple food intake in a number of West African countries remained unchanged in the face of doubling food prices and this led to an unhealthy reallocation of consumption out of meat and proteins for the purpose of affording more expensive rice consumption. By contrast, Aker, Block, Ramachandran and Timmer (2011) emphasize the possibility of greater willingness of consumers in the same West African region to switch to local staple food varieties in the context of the international staple price shocks of 2007-08, thus challenging stylized assumptions of negative net welfare implications of rising international food prices. While Diagana et al's (1999) study relies solely on descriptive statistics, Aker et al' s (2011) analysis is performed at the macroeconomic level, thus making it difficult to compare their results and thus draw a complete and rigorous picture of the micro level implications of price shocks.

A serious constraint to comprehensive research on the implications of price and general economic shocks on consumption and nutrition is the scarcity of rich enough data from developing countries which experienced severe price and income shocks, allowing the researcher to explore the shock's implications in a before and after manner. As a consequence, most of the policy prescriptions related to the possible effects of food price shocks are based on (i) simulations using Computable General Equilibrium Models, and (ii) 
studies trying to identify the impact of the price increase of a particular food item, for example, rice or wheat, on the welfare of net buyers of that particular food item. While providing a rigorous picture of the number and poverty levels of those affected by a price shock, conditional on everything else in the world remaining the same, these studies do not account for the possibility that a price shock may induce consumers to reallocate their food baskets towards cheaper food items, an action with ex ante unclear nutritional consequences.

In one of the more recent attempts to fill this gap in the literature, Ecker and Quaim (2010) take seriously into account the possibility that a price shock on specific food groups could induce reallocation of consumption and nutrition by estimating a full system of equations that accounts for the effect of the full vector of food prices, as well as income. However, as in the majority of studies in the area, their analysis is based on a single crosssection of data and corresponding simulations that assume unchanging food and nutrient elasticities, despite the possibility that severe price and/or economic shocks may induce a structural break and completely change consumer behaviour (Aker et al, 2011).

This paper fills some of the gaps outlined above and contributes to sorting out some of the existing controversies in the literature by using the natural experiment of Bulgaria in the mid-1990s to early 2000s. The context and timing are ideal for exploring the implications of severe income and price shocks, as well as the role of changing relative food prices on consumption and nutrition. Almost nowhere was the shock of structural reform and crisis as severe as in Bulgaria during the 1990s. The dissolution of the Council for Mutual Economic Assistance (CMEA), the war in former Yugoslavia, and policy stalemates, all led to a greater drop in output and higher inflation than in most other Central and East European (CEE) countries, culminating in the crisis of 1996-97. Between 1995 and 1996 the country experienced a hyperinflation, with the annual consumer price index increasing by $2467 \%$. Poverty incidence increased by 77\% (Sahn, Younger and Myerhoefer, 2002), while the fall in 
food consumption exceeded that of the majority of the CEE countries (Elsner and Hartmann, 1998).

There is evidence that consumption of commercially produced bread and meat must have been the most affected, as both income decline and agricultural sector problems made the production of grains and livestock especially problematic and contributed to significant increase in their prices (Ivanova, Dimitrov, Ovcharova, Dellava and Hoffman, 2006). According to OECD (1997) the broader economic crisis in Bulgaria in the mid-1990s was accompanied by a 'bread crisis'. The price of a standard white bread loaf increased most significantly by $3380 \%$, from 15.66 levs in 1995 to 545 levs in 1997 . There was a spillover of the grain crisis into a general food crisis, exemplified for instance by a $2509 \%$ increase in the price of a $\mathrm{kg}$ of pork from 204.10 levs in 1995 to 5325 levs in 1997 and a1785\% increase in the price of a kg of beef from 158.44 levs in 1995 to 2988 levs in 1997 (National Statistical Office of Bulgaria, 2000). The introduction of a currency board ensured macroeconomic stabilization, such that between 1997 and 2001 the inflation was only $30 \%$.

With the use of rich and uniquely timed data - from before the crisis of 1996, through the crisis of 1996-97, until the much more stable year 2001 - we explore the reaction of household consumption and nutrition to changing food prices and incomes. We not only take the whole set of relevant food prices and incomes into account in estimating a system of demand equations, but are also able to compare the nutritional implications of economic crises with those of more stable economic environments, characterised by significantly lower price inflations. We find that while demand for foodstuffs may remain relatively unchanging in environments characterised by stable food prices and incomes, economic crises and significant price spikes appeared to induce dramatic changes in price and income demand elasticities. We therefore suggest the use of caution in basing policy prescriptions on randomly available pre-crisis simulations. 
In section 2 we provide a description of the general economic background of this study on Bulgaria and present some consumption and nutrient statistics. In section 3 we outline the methodologies used to estimate price and income elasticities of food and nutrients and discuss our results on income and price elasticities of key food groups and nutrients. Section 4 concludes.

\section{The story of consumption and nutrition in Bulgaria}

The main data sources for our analysis are the Living Standards Measurement Surveys (LSMS) for 1995, 1997 and 2001, provided by the World Bank ${ }^{1}$. The surveys provide detailed information on monthly food consumption and expenditures, total expenditures and incomes, demographic and other characteristics of interest. After accounting for missing observations, we have 2028 households in 1995, 1161 households in 1997, and 1858 households in 2001. We supplement these data with data on the nutrient composition of all food groups consumed, collected by the National Centre of Public Health Protection in Bulgaria $^{2}$.

As a prelude to our rigorous empirical analysis we take a look at the impact of the changes in incomes and prices, highlighted at the outset, on food consumption and nutrition. Table 1 highlights the percentage changes in the food basket and the macro-nutrient composition of the food basket of the average household between 1995 and 1997 and between 1997 and 2001. We see that between 1995 and 1997, the consumption basket allocated out of fruits, vegetables and dairy products into bread, while the budgetary outlay on meat and starches remained roughly the same. By 2001, the consumption patterns moved back towards their 1995 levels. A possible explanation of the significant increase in the budget share of bread in the face of rising prices is possibly a reflection of the inelastic demand for bread, which is the main staple food in the Bulgarian diet. 
When looking at the effect of this reallocation of budgetary shares on nutrition, when expressed in calorie shares of each macronutrient of interest, we see that, aside from a slight reduction of the share of proteins and fat and a very minor increase in the share of carbohydrates, these shares remained almost unchanged. This is consistent with the argument of Stillman and Thomas (2008) that people reacted to the crisis by reallocating their diets in a way that keeps their nutrient composition virtually unchanged. However, looking at the actual amount of calories consumed and the actual quantities (in grams) of macronutrient consumed we see that the total quantity of macronutrients consumed by households went down observably. In other words, the crisis did have an impact on the actual quantity of nutrients consumed with potential implications for health and nutrition, despite the strong impact of consumer preferences on preserving the nutrient composition.

$<<<<<<<<$ Insert Table 1 about here $>>>>>>$

However, as argued earlier, the effects of price shocks should not be assessed in isolation from other influences, most importantly those of changing incomes and prices of alternative food groups. Indeed, while the price of bread increased proportionally more than the price of say meat, incomes also declined while the absolute price of a kilogram of meat remained significantly higher than the absolute price of bread. Hence, in analysing the effect of rising staple food prices, it is imperative to take account of the inter-related effects of changing incomes and prices.

\section{Estimation of income and price elasticities of food demand}

\subsection{Non-technical description of the methodology used}

One of the most controversial and challenging areas of economic research is the unbiased estimation of the responsiveness of demand for food and nutrition to changing prices and incomes. While the literature on developed countries has been able to rely on long 
time series of price and consumption data and an environment of highly developed distributional and transport networks to identify price variations over time, lack of data and integrated markets have made this approach infeasible in the context of developing countries (Deaton, 1997). Indeed, as evidenced by FAO (1997), one of the largest political triggers of the 'food crisis' in Bulgaria during the 1990s was the spatial variation of food prices.

Although data on regional price variation is sometimes available by national statistical offices and can potentially be merged with household surveys to estimate income and price elasticities of demand, with only few data collection sites available, such data may provide inaccurate estimates of the prices faced by individual households. To overcome this problem, the literature (in the tradition of Deaton, 1987a; 1987b; 1990) has mostly relied on unit values, calculated as the ratio of food expenditures and quantities of food consumed, to infer price elasticities of demand. The basic idea is that market prices are treated as unobservable variables, which directly determine the quantities purchased and are at the same time implied by the unit values. The key problems of using unit values to 'imply' prices are that (i) unit values reflect quality choices, which are in turn affected by the prices; hence while prices affect the unit values of goods, unit values vary less than proportionately with prices, and (ii) because both expenditures and quantities are measured with error, the unit values are also error ridden.

Since the earliest incarnations of the model, Deaton has used standard household survey structures to identify the separate effects of measurement error and variation in market price. The key idea is that households are seen as belonging to 'clusters', that is, in the same village, usually of about twelve households, and can easily be visited by the enumerators at the same time. The crucial (and reasonable!) assumption is that there is no variation in market prices within the cluster, such that the within-cluster estimators of unit value and quantity equations can identify consumption and quality effects without being contaminated by 
unobserved variation in market prices. These within cluster estimators can then be used to calculate the effect of measurement error, as within the clusters only spurious variances and covariances will be present. The demand system of equations itself is then estimated from inter-cluster variations in corrected quantities and unit values, after accounting for the predicted effects of measurement errors.

While Deaton's original model suffers from reliance on log-linear demand specifications, meaning that its demand functions may not add up to total expenditures, later extensions (for example, Deaton, 1990) model quality effects in the sense of Prais-Houtakker (1955), which is incompatible with the Almost Ideal Demand System. In this paper, we use the Crawford, Laisney and Preston (2003) model, which is to the best of our knowledge the most sophisticated demand system of equations model using unit value to infer price elasticities of demand. The approach we follow is in the tradition of - and addressing methodological issues in - Deaton (1987a, 1987b, 1990), employing a relationship between unit value and quality under an assumption of weak separability of preferences. This allows partitioning of food consumption into a number of separate groups where a change in the price of one group affects the demand for all commodities in another group. The model shares the key characteristics of the Almost Ideal Demand System of Deaton and Muellbauer (1980). Among its most useful advantages are the facts that (i) it can be used to test the restrictions of homogeneity and symmetry, using linear restrictions on fixed parameters, and (ii) the log-linear approximation of the price index allows the modeller to avoid the nonlinearity assumption that would defeat the within-cluster estimation adopted in the estimation strategy.

A summary of the mathematical formulation of the Crawford et al (2003) model is provided in Appendix 1 at the end of this paper, while the actual results from the intermediate estimation stages are available in the online appendix and in a very early working paper 
version of this $\operatorname{article}^{3}$. Here we summarise our steps. Following closely Crawford et al's (2003) econometric methodology and empirical specification we first define seven different food groups (bread, starches, fruits and vegetables, meat, oil and fat, dairy products and sweets) and obtain within-cluster estimates of Engel curve and unit value equations as functions of unobserved prices and total expenditures/quantities consumed (equations A6 and A7 in Appendix 1). In keeping with Crawford et al (2003), it may be unreasonable to assume that there is a connection between the availability of food quantity information (related to the survey design) and the structure of preferences. We therefore assume that these preferences are not separable in the corresponding partitions and hence condition the budget shares of the modelled foods on the expenditures of the non-food and non-modelled foods ${ }^{4}$. We also condition the budget shares on durable goods ownership. Following Blundell and Robin (2000), we do not condition the budget shares on the labour market status of the household, which implies separability of preferences between leisure and modelled foods. Our test of separability between leisure and the modelled foods, based on the inclusion of a dummy variable of labour force participation of the head of household, is available upon request ${ }^{5}$.

The within-cluster estimation allows the cancelling of the unobserved price effects (equations A8 and A9 in Appendix 1). Among the most notable results in this first step in the estimation is the significant association between the unit value and the quantity consumed, which gives credence to the use of this method. In the second stage we estimate the price coefficients using between cluster information (see the explanation in Appendix 1), while in the last stage we impose symmetry by minimum distance estimation and calculate the corresponding own, cross-price elasticities and income elasticities of demand. The results from the Engel curve and unit value estimations can be found in the online appendix.

\subsection{Key food demand results}


One of the key research questions we try to answer is whether relying on a crosssection of data, for example, a year or two before a crisis, we can draw an accurate picture of the effects of shocks on food consumption and nutrition as a result of the crisis. Our estimation therefore proceeds in two steps. First, we calculate the price and income elasticities of demand for each of the three annual cross-sections of data available to us. Second, we pool the three cross-sections of data and test for structural breaks between 1995 and 1997, and between 1997 and 2001. The potential advantage of pooling the data would be that our estimates are based on a larger pool of obsevations, including information from the crisis period itself. However, pooling of the data implies the existence of a unique regime of prices across the three years, which may be questionable in the period studied, especially given the incidence of hyperinflation between 1995 and 1997. If the existence of structural break(s) is confirmed, pooling of the data would not be justified empirically and we would not be able to draw policy inferences from the pooled sample.

\section{$\langle<<<<<<<$ Insert Table 2 about here $>>>>>>$}

In Table 2, we highlight our cross-sectional estimates of price and income elasticities of demand. The results indicate that across the three cross-sections, income elasticities of demand for food groups are positive and significant, highlighting the 'normal good' status of bread, starches, oil and fat and dairies and the 'luxury' status of meat, fruit and vegetables, and sweets. At the same time, we observe a significant change in price elasticity estimates across the cross-sections, most notably between 1995 and 1997, emphasizing the possible presence of a structural break. Focusing on the effect of a change in the price of bread, we see that while in 1995 the cross-elasticity of demand for bread was positive and insignificant, highlighting the usual assumption in the literature on food crises that consumption of key staple foods is likely to remain unchanged even in hyperinflationary environments. By 1997 and 2001 the own price elasticities of demand for bread become negative and significant, 
indicating the possible relocation of the consumption basket out of more expensive staple foods. Similarly, while the cross-price elasticities of demand for bread in 1997 and 2001 indicate reallocation of the consumption basket out of bread, starches and dairies into meat, fruit and vegetables and sweets in the event of an increase in the price of bread, the 1995 cross-price elasticities indicate a reallocation of consumption into starches and oil and fat. These differences in cross-price elasticities highlight differences in nutrient response in the event of rising staple food prices, with potentially important methodological and policy implications.

\section{$\langle<<<<<<<$ Insert Table 3 about here $>>>>>>$}

To verify whether the results are indeed structurally different, we test for a structural break and highlight the results of the test in Table 3. These results confirm our observations from Table 2 that while the price elasticities were fairly stable between 1997 and 2001, the much more observable instability in estimates between 1995 and 1997 is consistent with our hypothesis of a structural break, casting doubt on the feasibility of pooling the cross-sections together and estimating price and income elasticities of demand for the whole sample. We therefore refrain from reporting results based on a pooled data sample and base our nutrient elasticity estimates on the cross-sectional food demand estimations.

\subsection{Estimation of income and price elasticities of nutrients}

Our results on food elasticities of demand indicate that a structural break between 1995 and 1997 makes pooling our three years of data to derive elasticities of demand problematic. We ask now whether using cross-sectional data from before the crisis and simulating the effect of the crisis gives a reasonable confirmation of results derived from our descriptive statistics. More importantly, we focus on the policy implications with respect to our end variable of interest, namely nutrition. 


\section{$<<<<<<<<$ Insert Table 4 about here $\gg>>>>>$}

To derive nutrient elasticities, we apply Huang's (1996) method, which uses elasticities from standard demand analysis to estimate elasticities of changes in the nutritional content of consumer diets (see Appendix 2). Table 4 highlights the macro nutrient elasticity estimates for all three cross-sections and for the pooled sample. Not surprisingly, given our finding of a structural break in the demand system of equations between 1995 and 1997, we see that the nutrient elasticities derived from the corresponding food elasticities of demand differ significantly between 1995 and 1997. In particular, the 1995 estimates highlight a significant increase in the consumption of calories and fat as a consequence of an increase in staple food prices, a pattern consistent with the degenerative health consequences of shocks highlighted in the nutritional literature, while the 1997 estimates highlight a decrease in the consumption of all key macronutrients, which is consistent with our observation of an overall decrease in the quantities of calories, proteins, carbohydrates and fat highlighted in Table 1.

These swap in elasticity signs casts doubt on the meaningfulness of performing simulations, based on a single cross-sectional estimate of price elasticities. Indeed, they cast doubt on any simulation based on an assumption about a potential price change which does not take into account either the potential cross-price and income effects on reallocation of consumption or the possibility that price and income elasticities themselves may change due to the shock. They are consistent with the general mistrust towards simulation based results in the recent literature on consumer reaction to changing food prices (deJanvry and Sadoulet, $2008)^{6}$

\section{Conclusion}

One of the most challenging areas of economic analysis and policy making today is the appropriate estimation of the reaction of food consumption and nutrition to price and 
income shocks and the appropriate policy response to these changes. While competition from bio-fuels and climate change are predicted to lead to rising and/or fluctuating food prices in the foreseeable future, and both price and income fluctuations are among the greatest hurdles to successful world poverty alleviation, there is little understanding among economists on exactly how large the effects of price and income fluctuations can be. To give an example about the debate in the empirical literature, recent simulation based research has predicted dramatic deterioration of consumption and nutrition on account of doubling of staple food prices (e.g. Policy Research Working Paper series 4738-4745 (World Bank); Zezza, Davis, Azzarris, Covarubia, Tasciotti and Anriquez, 2008), even though barometer based opinion surveys have found the consequences of price fluctuations to be far smaller (Headey, 2011; Verpoorten, Arora and Swinnen, 2012).

We provide some further insights into this subject by exploring the particularly interesting case of Bulgaria over the 1990s, which allows us to track consumer behaviour through the crisis of 1996 (characterized by its significant increase in staple food prices as well as major income reduction) and then again through the more turmoil free period thereafter. One of our most notable findings is that a structural break between 1995 and 1997 induces a significant change, in fact a swap in sign of price elasticities of demand across a few key consumption items. As a result, we warn against blind simulation based predictions that rely on single cross-sections of data, prior to periods of dramatic price and income fluctuations.

Our empirical results and related story line are consistent with recent critiques to the use of simulation based analyses in the literature on consumer behaviour. While the main concern expressed in this literature is that simulation analyses (i) rely on assumed, as opposed to actual price changes and such assumptions may end up being incorrect in practice, and (ii) tend to produce ceteris paribus estimates of quantity changes as a reaction to the change in one price at a time, thus ignoring the possibility that alternative prices and incomes also 
change as a reaction to the shock (deJanvry and Sadoulet, 2008). We add to this list the possibility that a shock may induce a structural break that changes the very behaviour of consumers and -consequently - the corresponding price and income elasticities of demand.

The case of Bulgaria may be unique in that data existed from before, during and years after a crisis and one could argue that periods of hyperinflation are not comparable to periods of moderate increase of prices, even in the dimension of the recent 2008 fluctuations. However, robustness checks and uses of different methodologies and data are required for informed policy predictions. For example, macro-based analyses a la Aker et al (2011) could provide at least some understanding on whether a crisis induces a structural break and hence whether household level elasticity estimates prior to the crisis are reliable. Policy makers should complement any such estimates with comprehensive descriptive statistics, barometer based and food diary surveys, that assess the actual 'field level' response of individuals to price and income shocks.

\section{Endnotes}

${ }^{1}$ For details, see: http://go.worldbank.org/PDHZFQZ6L0. While a survey for 2003 is also available, it differs significantly from the three earlier surveys making comparisons across the four cross-sections difficult. The Bulgarian economy stabilized significantly after 2000 and we do not expect major changes to have taken place between 2001 and 2003 in the phenomena and indicators in which we are interested.

${ }^{2}$ We thank Ludmila Ivanova and Plamen Dimitrov for making these data available to us.

3 For details on the results from the first stages in our analysis you could see the online appendix as well as a very early version of this paper: http://www.iza.org/en/webcontent/publications/papers/viewAbstract?dp_id=5610 
4 These include tobacco, hygiene related goods, energy, transport and communications, recreation, housing, clothes and shoes, furniture, health. A full list of the products used can be found in the working paper version mentioned in footnote 3 .

${ }^{5}$ Homogeneity with respect to the prices of excluded goods is imposed by expressing the conditioning expenditures in relative terms with respect to the expenditures of non-modelled food. Following Crawford et al (2003) we also take care of the problem of zero conditioning expenditures by introducing dummies which take the value of one if the expenditures on conditioning goods are zero.

${ }^{6}$ For instance, in our specific case a typical simulation exercise would have produced estimates of a reaction of the quantity of macronutrients consumed, assuming say doubling of the price of bread, keeping everything else unchanged. A simulation based on 1995 elasticity estimate would have led us to believe that the quantity of each macronutrient consumed would have gone up on account of doubling bread prices. In either case, the actual quantity change estimated would be unreliable due to ignoring the potential countervailing effect of changes of alternative prices and incomes and- in turn- their respective effect on macronutrient quantity changes. 


\section{References}

Aker, J., Block, S., Ramachandran, V. \& Timmer, C. (2011)West African Experience with the World Rice Crisis, 2007-2008. Center for Global Development Working Paper 242.

Blundell, R., \& Robin, J-M. (2000). Latent separability: grouping foods without weak separability. Econometrica, 68, 53-84.

Crawford, I., Laisney, F., \& Preston, I. (2003). Estimation of household demand system with theoretically compatible Engel curves and unit value specification. Journal of Econometrics, 114, 221-241.

Deaton, A.S. (1987a). Estimation of own and cross-price elasticities from household survey data. Journal of Econometrics, 36, 3-7.

Deaton, A.S. (1987b). Quality, quantity and spatial variation of price: estimating price elasticities from cross-sectional data. Living Standards Measurement Study Working Paper 30.

Deaton, A.S. (1990). Prices elasticities from survey data: extension and Indonesian results. Journal of Econometrics, 44, 281-309.

Deaton, A.S. (1997). The analysis of household surveys. A microeconomic approach to development policy. Washington, DC: The International Bank for Reconstruction and Development.

Deaton, A.S., Mullbauer, J.N.J. (1980). Economics and consumer behavior. Cambridge: University Press.

deJanvry, A., Sadoulet, E. (2008). Methodological note: Estimating the effects of the food price surge on the welfare of the poor. http://are.berkeley.edu/ esadoulet/papers/FoodPriceMethodologyDec08.pdf 
Diagana, B., Akindès, F., Savadogo, K., Reardon, T., \& Staatz, J. (1999). Effects of CFA franc devaluation on urban food consumption in West Africa: overview and crosscountry comparisons. Food Policy, 24, 465-478.

Ecker, O. and Qaim, M. (2010). Analysing nutritional impacts of policies. An Empirical study for Malawi. IFPRI Discussion Paper 01017.

Elsner, K. \& Hartmann, M. (1998). Convergence of food consumption patterns between Eastern and Western Europe. Institute of Agricultural Development in Central and Eastern Europe.

FAO (1997). Special Report: Food Supply and Nutritional Situation Assessment In Bulgaria: http://www.fao.org/docrep/004/w4932e/w4932e00.HTM.

Frankenberg, E., Thomas, D. \& Beegle, K. (1999). The real cost of Indonesia's economic crisis: preliminary findings from the Indonesia Family Life Survey. Rand Labor and Population Program Working Paper Series 95-04.

Heady, D. (2011). Was the global food crisis really a crisis? Simulations versus selfreporting. IFPRI Discussion Paper 01087, International Food Policy Research $\begin{array}{llll}\text { Institute } & \text { (IFPRI). }\end{array}$ http://www.ifpri.org/sites/default/files/publications/rb17.pdf

Huang, K.S. (1996). Nutrient elasticities in a complete demand system. American Journal of Agricultural Economics, 78, 21-29.

Ivanova, L., Dimitrov, P., Ovcharova, D., Dellava, J., \& Hoffman, D.J. (2006). Economic transition and household food consumption: a study of Bulgaria from 1985 to 2002. Economics and Human Biology, 4, 383-397.

McKelvey. C. (2011). Price, unit value and quality demanded. Journal of Development Economics, 95, 157-169. 
National Statistical Institute of Bulgaria (2000). Average Prices and Quantities Consumed of Food and Non-Food Items by Bulgarian Households. Sofia, Bulgaria.

OECD (1997). Economic Surveys Bulgaria 1996/1997. Volume 1997, Issue 7. Paris.

Prais, S.J., \& Houtakker H.S. (1955). The analysis of family budgets. Cambridge: Cambridge University Press.

Sahn D., Younger, S., \& Meyerhoefer, C. (2002). Rural poverty in Bulgaria: characteristics and trends. CFNPP Working paper No 132, Cornell University.

Stillman, S. (2006). Health and nutrition in East Europe and the former Soviet Union during a decade of transition. A review of the literature. Economics and Human Biology, 5, 104-146.

Stillman, S., and Thomas, D. (2008). Nutritional status during an economic crisis: evidence from Russia. Economic Journal, 118, 1385-1417.

Verpoorten, M., Arora, A. and Swinnen, J. (2012). Self-reporting food insecurity in Africa during the food price crisis. LICOS Discussion Paper Series 303: https://www.econ.kuleuven.be/licos/DP/DP2012/DP303.pdf

Zezza, A., Davis, B., Azzarris, C. Covarubia, K., Tasciotti, L and Anriquez, G. (2008). The impact of rising food prices on the poor. ESA Working Paper 07-08, FAO: ftp://ftp.fao.org/docrep/fao/011/aj284e/aj284e00.pdf 
Table 1: Changes in the budget and nutrient share of key food groups, 1995-1997-2001

\begin{tabular}{|c|c|c|c|}
\hline & 1995 & 1997 & 2001 \\
\hline \multicolumn{4}{|c|}{ Food shares in the budget } \\
\hline Bread & $0.0993(0.0732)$ & $0.1967(0.1163)$ & $0.1459(0.0967)$ \\
\hline Starches & $0.1189(0.0655)$ & $0.1198(0.0808)$ & $0.1237(0.0716)$ \\
\hline Fruit and vegetables & $0.2304(0.1143)$ & $0.1758(0.1210)$ & $0.1836(0.1038)$ \\
\hline Meat & $0.2579(0.1235)$ & $0.2440(0.1355)$ & $0.2428(0.1251)$ \\
\hline Fat & $0.0470(0.0369)$ & $0.0397(0.0323)$ & $0.0509(0.0319)$ \\
\hline Dairy & $0.1936(0.1074)$ & $0.1730(0.1005)$ & $0.1909(0.1005)$ \\
\hline Sweets & $0.0588(0.0452)$ & $0.0510(0.0487)$ & $0.0621(0.0516)$ \\
\hline \multicolumn{4}{|c|}{ Macro-nutrient quantities } \\
\hline $\begin{array}{l}\text { Calories (a day per } \\
\text { person) }\end{array}$ & $2618(3260.57)$ & $2303.65(1426.46)$ & $2175.04(959.88)$ \\
\hline $\begin{array}{l}\text { Protein (grams a day } \\
\text { per person) }\end{array}$ & $112.27(135.55)$ & $93.80(59.50)$ & $91.23(39.77)$ \\
\hline $\begin{array}{l}\text { Fat (grams a day per } \\
\text { person) }\end{array}$ & $112.28(296.39)$ & $90.41(62.04)$ & $92.74(52.57)$ \\
\hline $\begin{array}{l}\text { Carbohydrates (grams } \\
\text { a day per person) }\end{array}$ & $284.12(146.16)$ & $262.88(210.99)$ & $240.65(110.63)$ \\
\hline \multicolumn{4}{|c|}{ Macro-nutrient share in total calories } \\
\hline Proteins & $0.1752(0.0251)$ & $0.1637(0.0246)$ & $0.1690(0.0247)$ \\
\hline Fats & $0.3665(0.0812)$ & $0.3516(0.0834)$ & $0.3798(0.0816)$ \\
\hline Carbohydrates & $0.4512(0.0784)$ & $0.4592(0.0784)$ & $0.4461(0.0772)$ \\
\hline $\mathrm{N}$ observations & 2028 & 1161 & 1858 \\
\hline
\end{tabular}

Note: The figures in brackets are standard deviations. 
Table 2. Food elasticities of demand

\begin{tabular}{|c|c|c|c|c|c|c|c|c|}
\hline \multicolumn{9}{|c|}{1995} \\
\hline & Bread & Starches & Fruit-veg & Meat & Oil and fat & Dairy & Sweets & Income \\
\hline Bread & $\begin{array}{l}0.0826 \\
(0.1284)\end{array}$ & $\begin{array}{l}0.4000 * * * \\
(0.0749)\end{array}$ & $\begin{array}{l}-0.0697 \\
(0.0764)\end{array}$ & $\begin{array}{l}0.0908 \\
(0.0981)\end{array}$ & $\begin{array}{l}0.3043 * * * \\
(0.0527)\end{array}$ & $\begin{array}{l}0.0300 \\
(0.0573)\end{array}$ & $\begin{array}{l}0.1728 * * * \\
() .0478)\end{array}$ & $\begin{array}{l}0.5390 * * * \\
(0.1552)\end{array}$ \\
\hline Starches & $\begin{array}{l}0.2952 * * * \\
(0.0587)\end{array}$ & $\begin{array}{l}0.0339 \\
(0.0888)\end{array}$ & $\begin{array}{l}-0.1638 * * * \\
(0.0623)\end{array}$ & $\begin{array}{l}-0.2348 * * * \\
(0.0749)\end{array}$ & $\begin{array}{l}0.1626 * * * \\
(0.0410)\end{array}$ & $\begin{array}{l}0.1777 * * * \\
(0.0498)\end{array}$ & $\begin{array}{l}0.1313 * * * \\
(0.0388)\end{array}$ & $\begin{array}{l}0.5773^{* * * *} \\
(0.1269)\end{array}$ \\
\hline Fruit-veg & $\begin{array}{l}-0.2467 * * * \\
(0.0321)\end{array}$ & $\begin{array}{l}-0.1339 * * * \\
(0.0321)\end{array}$ & $\begin{array}{l}-0.5726 * * * \\
(0.0551)\end{array}$ & $\begin{array}{l}0.1013 * * * \\
() .0439)\end{array}$ & $\begin{array}{l}-0.0627 * * * \\
(0.0187)\end{array}$ & $\begin{array}{l}-0.3324 * * * \\
() .0340)\end{array}$ & $\begin{array}{l}-0.0606 * * * \\
(0.0206)\end{array}$ & $\begin{array}{l}1.1954 \text { *** } \\
(0.1767)\end{array}$ \\
\hline Meat & $\begin{array}{l}-0.0398 \\
(0.0353)\end{array}$ & $\begin{array}{l}-0.1774 * * * \\
(0.0345)\end{array}$ & $\begin{array}{l}0.0523 \\
(0.0391)\end{array}$ & $\begin{array}{l}-1.1257 * * * \\
(0.0623)\end{array}$ & $\begin{array}{l}-0.1318 * * * \\
() .0231)\end{array}$ & $\begin{array}{l}-0.2164 * * * \\
(0.0357)\end{array}$ & $\begin{array}{l}-0.1912 * * * \\
(0.0216)\end{array}$ & $\begin{array}{l}1.2916^{* * * *} \\
(0.0932)\end{array}$ \\
\hline Oil and fat & $\begin{array}{l}0.5930 * * * \\
(0.1047)\end{array}$ & $\begin{array}{l}0.4210^{* * *} \\
(0.1040)\end{array}$ & $\begin{array}{l}-0.1939 * * * \\
(0.0922)\end{array}$ & $\begin{array}{l}-0.5536 * * * \\
(0.1275)\end{array}$ & $\begin{array}{l}0.0244 \\
(0.1557)\end{array}$ & $\begin{array}{l}0.3259 * * * \\
(0.0743)\end{array}$ & $\begin{array}{l}0.1455 * * * \\
(0.0710)\end{array}$ & $\begin{array}{l}0.6698 * * * \\
(0.2063) \\
\end{array}$ \\
\hline Dairy & $\begin{array}{l}-0.0177 \\
(0.0274)\end{array}$ & $\begin{array}{l}0.0917 * * * \\
(0.0307)\end{array}$ & $\begin{array}{l}-0.3336^{* * * *} \\
(0.0408)\end{array}$ & $\begin{array}{l}-0.1762^{* * * *} \\
(0.0480)\end{array}$ & $\begin{array}{l}0.0685 * * * \\
(0.0179)\end{array}$ & $\begin{array}{l}-0.0075 \\
(0.0583)\end{array}$ & $\begin{array}{l}0.0115 \\
(0.0188)\end{array}$ & $\begin{array}{l}0.8101 \text { *** } \\
(0.1448)\end{array}$ \\
\hline Sweets & $\begin{array}{l}0.2259 * * * \\
(0.0759)\end{array}$ & $\begin{array}{l}0.2276 * * * \\
(0.0786)\end{array}$ & $\begin{array}{l}-0.2158 * * * \\
(0.0812)\end{array}$ & $\begin{array}{l}-0.7716 * * * \\
(0.0954)\end{array}$ & $\begin{array}{l}0.0976 \\
(0.0567) \\
\end{array}$ & $\begin{array}{l}0.0043 \\
(0.0622)\end{array}$ & $\begin{array}{l}-0.0745 \\
(0.0784)\end{array}$ & $\begin{array}{l}1.3837 \text { **** } \\
(0.2146)\end{array}$ \\
\hline \multicolumn{9}{|c|}{1997} \\
\hline Bread & $\begin{array}{l}-1.1032 * * * \\
(0.1144)\end{array}$ & $\begin{array}{l}-0.2573 * * * \\
(0.0602)\end{array}$ & $\begin{array}{l}0.2078 * * * \\
(0.0473)\end{array}$ & $\begin{array}{l}0.3101 * * * \\
(0.0930)\end{array}$ & $\begin{array}{l}-0.0392 \\
(0.0261)\end{array}$ & $\begin{array}{l}-0.1767 * * * \\
(0.0600)\end{array}$ & $\begin{array}{l}0.1631 * * * \\
(0.0389)\end{array}$ & $\begin{array}{l}0.3642 * * * \\
(0.0417)\end{array}$ \\
\hline Starches & $\begin{array}{l}-0.4964 * * * \\
(0.0991)\end{array}$ & $\begin{array}{l}-0.2107 \\
(0.1239)\end{array}$ & $\begin{array}{l}0.0177 \\
(0.0496)\end{array}$ & $\begin{array}{l}0.1541 \\
(0.0824)\end{array}$ & $\begin{array}{l}-0.1172 * * * \\
(0.0355)\end{array}$ & $\begin{array}{l}-0.3939 * * * * \\
(0.0731)\end{array}$ & $\begin{array}{l}-0.0811 \\
(0.0462)\end{array}$ & $\begin{array}{l}0.7416^{* * * *} \\
(0.0555)\end{array}$ \\
\hline Fruit-veg & $\begin{array}{l}0.0537 \\
(0.0534)\end{array}$ & $\begin{array}{l}-0.0516 \\
(0.0338)\end{array}$ & $\begin{array}{l}-0.6518 * * * \\
(0.0545)\end{array}$ & $\begin{array}{l}-0.6359 * * * \\
(0.0527)\end{array}$ & $\begin{array}{l}-0.0038 \\
() .0140)\end{array}$ & $\begin{array}{l}-0.1599 * * * \\
(0.0397)\end{array}$ & $\begin{array}{l}-0.0202 \\
(0.0214)\end{array}$ & $\begin{array}{l}1.2732^{* * * *} \\
(0.0547)\end{array}$ \\
\hline Meat & $\begin{array}{l}0.0177 \\
(0.0750)\end{array}$ & $\begin{array}{l}-0.0206 \\
(0.0403)\end{array}$ & $\begin{array}{l}-0.5058 * * * \\
(0.0375)\end{array}$ & $\begin{array}{l}-2.9962 * * * * \\
(0.0866)\end{array}$ & $\begin{array}{l}0.0284 \\
(0.0188) \\
\end{array}$ & $\begin{array}{l}0.2185 * * * \\
() .0447)\end{array}$ & $\begin{array}{l}-0.1344 * * * \\
(0.0305)\end{array}$ & $\begin{array}{l}1.5450 * * * \\
(0.0432)\end{array}$ \\
\hline Oil and fat & $\begin{array}{l}-0.2813^{* * * *} \\
(0.1301)\end{array}$ & $\begin{array}{l}-0.3620 * * * \\
(0.1073)\end{array}$ & $\begin{array}{l}0.0652 \\
(0.0626)\end{array}$ & $\begin{array}{l}0.3552 * * * \\
(0.1166)\end{array}$ & $\begin{array}{l}-0.2546 \\
(0.1355)\end{array}$ & $\begin{array}{l}0.0075 \\
(0.0975)\end{array}$ & $\begin{array}{l}0.0276 \\
(0.0806)\end{array}$ & $\begin{array}{l}0.8065^{* * * *} \\
(0.0700)\end{array}$ \\
\hline Dairy & $\begin{array}{l}-0.2997 * * * \\
(0.0684)\end{array}$ & $\begin{array}{l}-0.2879 * * * \\
(0.0505)\end{array}$ & $\begin{array}{l}-0.0910 * * * \\
(0.0402)\end{array}$ & $\begin{array}{l}0.4739 * * * \\
(0.0633)\end{array}$ & $\begin{array}{l}-0.0006 \\
(0.0223) \\
\end{array}$ & $\begin{array}{l}-0.3514 * * * \\
(0.0812)\end{array}$ & $\begin{array}{l}-0.1048 * * * \\
(0.0316)\end{array}$ & $\begin{array}{l}0.8663^{* * * *} \\
(0.0490)\end{array}$ \\
\hline Sweets & $\begin{array}{l}0.4814 * * * * \\
(0.1505)\end{array}$ & $\begin{array}{l}-0.2352 * * * \\
(0.1087)\end{array}$ & $\begin{array}{l}-0.0415 \\
(0.0744)\end{array}$ & $\begin{array}{l}-0.5377 \text { **** } \\
(0.1470)\end{array}$ & $\begin{array}{l}0.0093 \\
(0.0627)\end{array}$ & $\begin{array}{l}-0.3982 \text { *** } \\
(0.1078)\end{array}$ & $\begin{array}{l}-0.2227 \\
(0.1197)\end{array}$ & $\begin{array}{l}1.1136 \\
(0.0810)\end{array}$ \\
\hline \multicolumn{9}{|c|}{2001} \\
\hline Bread & $\begin{array}{l}-1.6604 * * * \\
(0.1056)\end{array}$ & $\begin{array}{l}-0.9794 * * * \\
(0.0728)\end{array}$ & $\begin{array}{l}-0.3259 * * * \\
(0.0523)\end{array}$ & $\begin{array}{l}0.1449 * * * \\
(0.0610)\end{array}$ & $\begin{array}{l}-0.4270 * * * \\
(0.0403)\end{array}$ & $\begin{array}{l}-0.8910 * * * \\
(0.0650)\end{array}$ & $\begin{array}{l}-0.0422 \\
(0.0402)\end{array}$ & $\begin{array}{l}0.5483 \text { *** } \\
(0.0371)\end{array}$ \\
\hline Starches & $\begin{array}{l}-1.1837 * * * \\
(0.0860)\end{array}$ & $\begin{array}{l}-1.6709 * * * \\
(0.1130)\end{array}$ & $\begin{array}{l}-0.3470 \text { *** } \\
(0.0557)\end{array}$ & $\begin{array}{l}0.1041 \\
(0.0613)\end{array}$ & $\begin{array}{l}-0.3089^{* * * *} \\
(0.0518)\end{array}$ & $\begin{array}{l}-0.6815^{* * * *} \\
(0.0674)\end{array}$ & $\begin{array}{l}-0.1064 * * * \\
(0.0474)\end{array}$ & $\begin{array}{l}0.7410 \text { *** } \\
(0.0370)\end{array}$ \\
\hline Fruit-veg & $\begin{array}{l}-0.3558 * * * \\
(0.0416)\end{array}$ & $\begin{array}{l}-0.2926 * * * \\
(0.0376)\end{array}$ & $\begin{array}{l}-0.4839 * * * \\
(0.0424)\end{array}$ & $\begin{array}{l}-0.0733 * * * \\
(0.0312)\end{array}$ & $\begin{array}{l}-0.1055^{* * * *} \\
(0.0191)\end{array}$ & $\begin{array}{l}-0.2115 * * * \\
(0.0345)\end{array}$ & $\begin{array}{l}-0.0673 * * \\
(0.0202)\end{array}$ & $\begin{array}{l}1.2101 \text { *** } \\
(0.0362)\end{array}$ \\
\hline Meat & $\begin{array}{l}-0.0241 \\
(0.0366)\end{array}$ & $\begin{array}{l}-0.0174 \\
(0.0312)\end{array}$ & $\begin{array}{l}-0.0739 * * * \\
(0.0234)\end{array}$ & $\begin{array}{l}-1.6309 * * * \\
(0.0362)\end{array}$ & $\begin{array}{l}0.0084 \\
(0.0183)\end{array}$ & $\begin{array}{l}0.0068 \\
(0.0344)\end{array}$ & $\begin{array}{l}0.0051 \\
(0.0181)\end{array}$ & $\begin{array}{l}1.3105 * * * \\
(0.0333)\end{array}$ \\
\hline Oil and fat & $\begin{array}{l}-1.2465 * * * \\
(0.1156)\end{array}$ & $\begin{array}{l}-0.7453^{* * * *} \\
(0.1259)\end{array}$ & $\begin{array}{l}-0.2861 * * * \\
(0.0692)\end{array}$ & $\begin{array}{l}0.1897 * * * \\
(0.0874)\end{array}$ & $\begin{array}{l}-0.3547 * * * \\
(0.1538)\end{array}$ & $\begin{array}{l}-0.5032 * * * \\
(0.0833)\end{array}$ & $\begin{array}{l}-0.1427 * * * \\
(0.0692)\end{array}$ & $\begin{array}{l}0.6941 \text { *** } \\
(0.0411)\end{array}$ \\
\hline Dairy & $\begin{array}{l}-0.7348^{* * * *} \\
(0.0496)\end{array}$ & $\begin{array}{l}-0.4631 \text { **** } \\
(0.0436)\end{array}$ & $\begin{array}{l}-0.1491 * * * \\
(0.0332)\end{array}$ & $\begin{array}{l}0.1046^{* * * *} \\
(0.0438)\end{array}$ & $\begin{array}{l}-0.1453 * * * \\
(0.0222) \\
\end{array}$ & $\begin{array}{l}-0.2552 * * * \\
(0.0555)\end{array}$ & $\begin{array}{l}-0.0754 * * * \\
(0.0236)\end{array}$ & $\begin{array}{l}0.9151 \text { *** } \\
(0.0348)\end{array}$ \\
\hline Sweets & $\begin{array}{l}-0.2024 * * * \\
(0.0947)\end{array}$ & $\begin{array}{l}-0.2756^{* * * *} \\
(0.0945)\end{array}$ & $\begin{array}{l}-0.2072^{* * * *} \\
(0.0603)\end{array}$ & $\begin{array}{l}0.0335 \\
(0.0715)\end{array}$ & $\begin{array}{l}-0.1455^{* * * *} \\
(0.0568)\end{array}$ & $\begin{array}{l}-0.2967 * * * \\
(0.0732)\end{array}$ & $\begin{array}{l}-0.7979 * * * \\
(0.0890)\end{array}$ & $\begin{array}{l}1.2543 \text { *** } \\
(0.0555)\end{array}$ \\
\hline
\end{tabular}

Note: Standard errors are in parentheses. $* * *, * *$ and $*$ mean statistically significant at $1 \%, 5 \%$, and $10 \%$, respectively. 
Table 3: Test for stability of results

\begin{tabular}{|c|c|c|c|c|c|c|c|}
\hline \multicolumn{2}{|l|}{ Price } & \multicolumn{6}{|c|}{ Wald test of stability of parameters } \\
\hline & & \multirow{2}{*}{\multicolumn{2}{|c|}{$\begin{array}{c}1995 \text { vs. } 1997 \\
71189 \\
\end{array}$}} & \multirow{2}{*}{\multicolumn{2}{|c|}{$\begin{array}{c}1997 \text { vs. } 2001 \\
7062.6\end{array}$}} & \multicolumn{2}{|c|}{1995 vs. 2001} \\
\hline \multicolumn{2}{|l|}{ All together } & & & & & & 358.5 \\
\hline \multicolumn{8}{|c|}{ Wald statistic of price effects: 1995 vs. 1997} \\
\hline & Bread & Starches & $\begin{array}{l}\text { Veg-and- } \\
\text { Fruit }\end{array}$ & Meat & $\begin{array}{l}\text { Fat-and- } \\
\text { Oil }\end{array}$ & Dairies & Sweets \\
\hline Bread & 31.07 & & & & & & \\
\hline Starches & 50.80 & 2.41 & & & & & \\
\hline $\begin{array}{l}\text { Veg-and- } \\
\text { Fruit }\end{array}$ & 9.38 & 6.32 & 5.39 & & & & \\
\hline Meat & 2.68 & 12.84 & 97.47 & 282.37 & & & \\
\hline Fat-and-oil & 30.16 & 26.23 & 8.17 & 31.93 & 3.98 & & \\
\hline Dairies & 15.59 & 41.43 & 24.04 & 68.63 & 6.51 & 19.64 & \\
\hline Sweets & 1.89 & 12.11 & 3.29 & 4.01 & 1.25 & 9.48 & 3.66 \\
\hline \multicolumn{8}{|c|}{ Wald statistic of price effects: 1997 vs. 2001} \\
\hline Bread & 0.32 & & & & & & \\
\hline Starches & 0.32 & 4.06 & & & & & \\
\hline $\begin{array}{l}\text { Veg-and- } \\
\text { Fruit }\end{array}$ & 1.69 & 0.86 & 0.10 & & & & \\
\hline Meat & 1.80 & 0.28 & 94.79 & 5.49 & & & \\
\hline Fat-and-oil & 0.65 & 0.27 & 1.12 & 0.72 & 0.007 & & \\
\hline Dairies & 0.36 & 0.17 & 0.13 & 9.74 & 0.91 & 0.05 & \\
\hline Sweets & 7.91 & 0.06 & 0.69 & 11.30 & 1.02 & 0.06 & 3.17 \\
\hline \multicolumn{8}{|c|}{ Wald statistic of price effects: 1995 vs. 2001} \\
\hline Bread & 3.62 & & & & & & \\
\hline Starches & 1.47 & 5.53 & & & & & \\
\hline $\begin{array}{l}\text { Veg-and- } \\
\text { Fruit }\end{array}$ & 0.51 & 0.20 & 0.001 & & & & \\
\hline Meat & 0.58 & 16.40 & 11.28 & 0.82 & & & \\
\hline Fat-and-oil & 1.95 & 2.06 & 0.06 & 18.62 & 0.22 & & \\
\hline Dairies & 0.92 & 1.35 & 1.43 & 9.35 & 2.00 & 0.12 & \\
\hline Sweets & 4.53 & 3.32 & 0.03 & 38.78 & 2.52 & 1.05 & 8.25 \\
\hline
\end{tabular}

Note: The upper part of the table tests for overall price stability, while the lower part of the table tests for stability of each price parameter separately. In the first case, the critical Wald statistics value is $\chi_{0.05}^{2}(28)=41.3 .7$. In the second case it is $\chi_{0.05}^{2}(1)=3.841$. 
Table 4: Nutrient elasticities

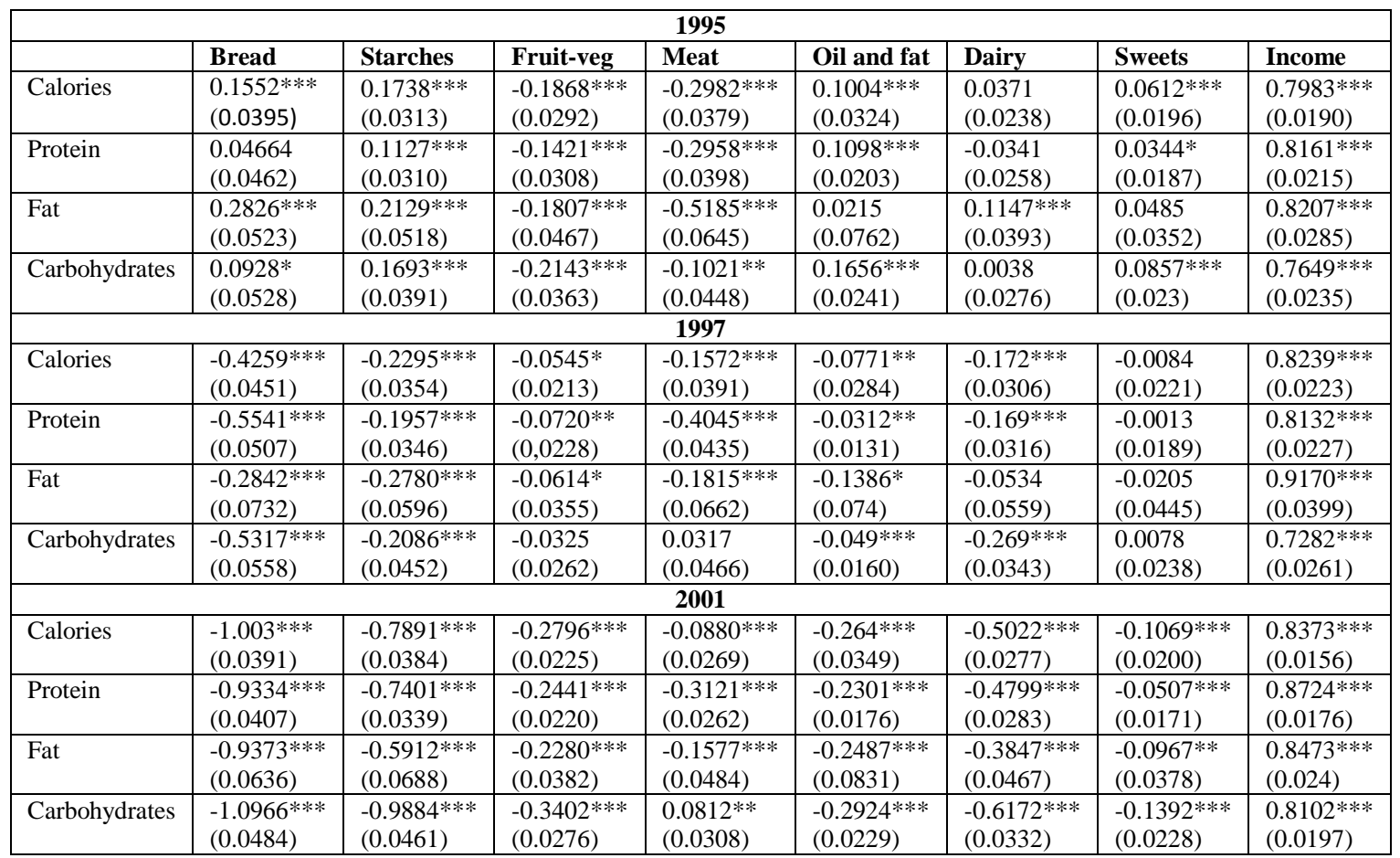

Note: Standard errors are in parentheses. $* * *, * *$ and $*$ mean statistically significant at $1 \%, 5 \%$, and $10 \%$, respectively. 


\section{APPENDIX 1: Further details on Methodology}

Here we provide a brief description of Crawford et al's (2003) methodology and discuss key results from stage one and two of the empirical analysis. The main advantage of the Crawford et al. (2003) model that we use to infer price elasticities from unit value information is that it allows us to exploit the explicit links between quantity and unit value in a way that is consistent with the Almost Ideal Demand System (AIDS) approach.

In keeping with the rest of the literature, foods are organized in $m$ groups (bread, starches, meat, and so forth). Under the assumptions of separability of preferences and homogeneity, we define the following relationship:

$V_{G}=\pi_{G} h_{G}\left(V_{G} Q_{G} / \pi_{G}\right)$,

where $V_{G}$ is the unit value for each group, $Q_{G}$ is the corresponding quantity index and homogeneous price index $\pi_{G}$ (for example, a Paasche price index), constructed based on the assumption of having a constant structure of relative prices within group G. Taking a double logarithm of [1] and given a functional form $\phi_{G}$ for the budget shares $w_{G}$, we therefore need to estimate a consistent system:

$$
\begin{aligned}
& \ln V_{G}=\ln \pi_{G}+\ln h_{G}\left[\frac{X}{\pi_{G}} \phi_{G}(X, \pi)\right], \\
& w_{G}=\phi_{G}(X, \pi),
\end{aligned}
$$

where $\mathrm{X}$ is total expenditures, and $\pi$ is a vector of group price levels (the omission of $\mathrm{G}$ indicates that these parameters refer to all groups). To make the estimation computationally tractable, a special functional form for $h_{G}$ is adopted such that

$$
\ln V_{G}=a_{G}+b_{G} \ln Q_{G}+\ln \pi_{G}
$$

As for the functional form of the demand function $\phi_{G}$, the model uses the approximate Almost Ideal Demand (AID) model with a log-linear approximation of the log 
index price (LA/AID). While the full AID specification or its quadratic extension would be preferable, the non-linear form would not be tractable by the within-cluster estimation adopted in this method. We attempt to extract at least some of the information that non-linear income specification would provide by estimating price and income elasticities for households belonging to different percentiles of total expenditures.

Assuming fixed prices for households located within a cluster $\mathrm{c}$, the demand function for group $\mathrm{G}$ by household $\mathrm{h}$ is:

$w_{G}^{h}=\alpha_{0 G}+\mathbf{Z}^{h} \boldsymbol{\alpha}_{G}+\sum_{H} \gamma_{G H} \ln \pi_{H}^{c}+\beta_{G} \ln \breve{x}^{h}+u_{G}^{h}$,

where $\breve{x}^{h}$ is deflated expenditure, $\ln \breve{x}^{h} \equiv \ln X^{h}-\ln P^{C} \equiv \ln X^{h}-\sum_{H} \lambda_{H} \ln \pi_{H}^{c}, \quad P^{c} \quad$ is a cluster price index with suitably chosen weights, $\pi_{H}^{c}$ is the price of group $H$ in cluster $c$. Equation (5) can be re-written as:

$w_{G}^{h}=\alpha_{0 G}+\mathbf{Z}^{h} \boldsymbol{\alpha}_{G}+\sum_{H} \delta_{G H} \ln \pi_{H}^{c}+\beta_{G} \ln X^{h}+u_{G}^{h}$,

where $\delta_{G H}=\gamma_{G H}-\beta_{G} \lambda_{H}$. Vector $\mathbf{Z}^{h}$ includes socio-demographic characteristics and other conditioning variables. Following the same logic, the unit value equation becomes:

$\ln V_{G}^{h}=a_{0 G}+\mathbf{Z}^{h} \mathbf{a}_{G}+\ln \pi_{G}^{c}+b_{G} \ln Q_{G}^{h}+v_{G}^{h}$

The estimation proceeds under the assumption of independence between observations, which is restrictive, given that the households are grouped by cluster and hence by construction common factors affect the demand for commodities within the cluster. However, under Lewbel's $(1993,1996)$ assumption of stochastic independence between relative good prices that are allowed to vary across clusters and the cluster price index, this cluster effect can be shown to be innocuous (Crawford et al., 2003). 
The estimation proceeds in three stages. In the first stage, we compute the withincluster estimates, which allow the cancelling of the unobserved price effects and retrieving the estimated vectors $\hat{\boldsymbol{\alpha}}_{G}$ and $\hat{\mathbf{a}}_{G}$, and the estimated scalars $\hat{\beta}_{G}$ and $\hat{b}_{G}$.

$$
\begin{aligned}
& \left(w_{G}^{h}-\bar{w}_{G}^{c}\right)=\left(\mathbf{Z}^{h}-\overline{\mathbf{Z}}^{c}\right) \boldsymbol{\alpha}_{G}+\beta_{G}\left(\ln X^{h}-\overline{\ln X}\right)^{c}+\left(u_{G}^{h}-\bar{u}_{G}^{c}\right), \\
& \left(\ln V_{G}^{h}-{\overline{\ln V_{G}}}^{c}\right)=\left(\mathbf{Z}^{h}-\overline{\mathbf{Z}}^{c}\right) \mathbf{a}_{G}+b_{G}\left(\ln Q_{G}^{h}-{\overline{\ln Q_{G}}}^{c}\right)+\left(v_{G}^{h}-\bar{v}_{G}^{c}\right) .
\end{aligned}
$$

2SLS estimation can be used to correct for the potential endogeneity of the variables in $\mathbf{Z}^{h}$.

The second stage consists of estimating the price coefficients $\gamma_{G H}$ using betweencluster information because the fixed nature of the within cluster price effects has already been used in the first stage. At this stage, we impose the standard homogeneity restriction in demand theory $\sum_{H} \gamma_{G H}=0$ (which implies also an adding-up restriction). Vector $\lambda$ is subject to positive linear homogeneity of the price index restrictions $\lambda_{G}>0$ and $\sum_{H} \lambda_{H}=1$. Since this is not sufficient to identify the parameters of interest, $\lambda$ arbitrarily set equal to $\overline{\mathbf{w}}$, the vector of average budget shares. The estimation of $\hat{\gamma}_{G}$ (the price effects in the budget equation for group G) also assumes homoscedasticity of the variance of $\left(\mathbf{u}^{h^{\prime}}, \mathbf{v}^{h^{\prime}}\right)$ and takes into account the measurement errors in the unit values. The resulting relationship is:

$$
\hat{\gamma}_{G}=\left[\sum_{c=1}^{c} n_{c} \zeta^{c} \zeta^{c^{\prime}}-\hat{\mathbf{\Omega}}_{v}\right]^{-1}\left[\sum_{c=1}^{c} n_{c}\left(\eta_{G}^{c} \zeta^{c}+\beta_{G} \zeta^{c} \zeta^{c} \boldsymbol{\lambda}\right)-\hat{\mathbf{\Omega}}_{v u_{G}}-\hat{\mathbf{\Omega}}_{\mathbf{v}} \boldsymbol{\lambda}\right],
$$

where,

$n_{c}$ is the size of each cluster $c$,

$$
\begin{aligned}
\eta_{G}^{c} & \equiv \bar{w}_{G}^{c}-\overline{\mathbf{Z}}^{c} \hat{\boldsymbol{\alpha}}_{G}-\hat{\beta}_{G} \overline{\ln X}^{c} \\
& =\alpha_{0 G}+\sum\left(\gamma_{G H}-\beta_{G} \lambda_{H}^{c}\right) \ln \pi_{H}^{c}+\bar{u}_{G}^{c},
\end{aligned}
$$




$$
\begin{aligned}
& \zeta^{c}=\left(\zeta_{1}^{c}, \ldots \zeta_{m}^{1}\right)^{\prime} \text {, with } \\
& \zeta_{G}^{c} \equiv{\overline{\ln V_{G}}}^{c}-\overline{\mathbf{Z}}^{c} \hat{\mathbf{a}}_{G}-\hat{b}_{G}{\overline{\ln Q_{G}}}^{c} \\
&=a_{0 G}+\ln \pi_{G}^{c}+\bar{v}_{G}^{c} \quad G=1, \ldots m, \text { and } \\
& \hat{V}\left(\begin{array}{c}
\bar{u}_{G}^{c} \\
\overline{\mathbf{v}}^{c}
\end{array}\right)=\frac{1}{n_{c}}\left[\begin{array}{cc}
\hat{\mathbf{\Omega}}_{u_{G}} & \hat{\mathbf{\Omega}}_{u_{G} \mathbf{v}} \\
\hat{\mathbf{\Omega}}_{\mathbf{v} u_{G}} & \hat{\mathbf{\Omega}}_{\mathbf{v}}
\end{array}\right], \text { where each term of } \hat{\boldsymbol{\Omega}} \text { is obtained from the first stage residuals. }
\end{aligned}
$$

The variance of price coefficients (without imposing symmetry) is obtained by the bootstrap procedure.

In the third stage, we impose the symmetry, $\gamma_{G H}=\gamma_{H G}$, by minimum distance estimation. By using the efficiency arguments of Kodde, Palm and Pfann (1990, theorem 5), we minimise only over $\gamma$ rather than over $\gamma$ and $\beta$.

Price elasticities are computed for household belonging to the $10^{\text {th }}, 25-50^{\text {th }}$ and $90^{\text {th }}$ expenditure percentiles using the formula $e_{G H}=\left(\gamma_{G H}-\beta_{G} \tilde{w}_{H}\right) / \widetilde{w}_{G}-1_{[G=H]}$; where $\widetilde{w}_{G}$ and $\tilde{w}_{H}$ represent the budget shares of group $G$ and group $H$ respectively. Total expenditure elasticities are also computed using the formula, $e_{G}=1+\beta_{G} / \widetilde{w}_{G}$.

The set of variables used in our analysis is described in the full technical appendix, available electronically. Our specifications are almost identical (to the extent it is possible for us to compare the two data sets) to the specifications used by Crawford et al (2003). We also attempted using the types of instruments suggested by these authors in trying to to account for the potential endogeneity of total expenditures, conditioning expenditures and durable goods. However, since the Durbin-Wu-Hausman test rejected the endogeneity hypothesis for any set of conceivable instruments, we estimate the budget share and unit value regression by OLS.

In Tables A2-A4 of the full technical appendix, we report the budget share estimates from the first stage of the empirical methodology. We see that during all years, total 
expenditures have a negative impact on the shares consumed of bread, starches, fats and oils and dairy products and a positive impact on the shares consumed of meat, fruit and vegetables and sweets. The rest of our results are consistent with any conventional assumptions. In so far as the unit value results (Tables A5-A7 of the full technical appendix) are concerned, the most valid result in our case is the significant effect of the food quantity variable in the unit value regression. This significant effect confirms the validity of our choice of methodology. The main body of the text discusses the price and income elasticities of demand for different food groups.

\section{Additional References to Appendix 1}

Kodde, D.A., Palm F.C., \& Pfann, G.A., 1990. Asymptotic least-squares estimation efficiency considerations and applications. Journal of Applied Econometrics, 5, 229243.

Lewbel, A., (1993). Stochastic Hicksian Aggregation with an application to grouping goods without separable utility. Annales d'Economie et de Statistique, 29, 17-42.

Lewbel, A., (1996). Aggregation without separability: a generalized composite commodity theorem. American Economic Review 86, 524-543.

\section{APPENDIX 2: Estimation of nutrient elasticities}

To derive nutrient elasticities, we apply of Huang's (1996) method, which uses demand elasticities from standard demand analysis to estimate elasticities of changes in the nutritional content of consumer diets. On the basis of the demand structure of food and the bundle of corresponding nutrient attributes it is possible to derive the implied relationship between nutrient availability and changes in food prices and incomes. Huang's approach provides information on how to derive the formula from an underlying demand model. 
Let $a_{k i}$ be the quantity of the $k^{\text {th }}$ nutrient obtained from a unit of the $G^{\text {th }}$ food group. The total quantity of that nutrient, $\psi_{k}$, obtained from various food groups can be expressed as:

$\psi_{k}=\sum_{G} a_{k G} Q_{G}$.

Equation (A11) represents the consumption technology in the sense of Lancaster (1966). It is straightforward to show that :

$$
\begin{aligned}
d \psi_{k} / \psi_{k} & =\sum_{H}\left(\sum_{G} e_{G H} a_{k G} Q_{G} / \psi_{k}\right)\left(d \pi_{H} / \pi_{H}\right)+\left(\sum_{G} e_{G} a_{k G} Q_{G} / \psi_{k}\right)(d X / X), \\
& =\sum_{H} D_{k H}\left(d \pi_{H} / \pi_{H}\right)+\rho_{k} d X / X
\end{aligned},
$$

where $D_{k H}=\sum_{G} e_{G H} a_{k G} Q_{G} / \psi_{k}$ is a price elasticity measure capturing the effect of the $H^{\text {th }}$ food group price on the availability of the $k^{\text {th }}$ nutrient; $\rho_{k}=\sum_{G} e_{G} a_{k G} Q_{G} / \psi_{k}$ is an income (or total expenditure) elasticity measure relating the effect of a change in income on the availability of that nutrient. In other words, the measurement of $D_{k H}$ represents the weighted average of all own- and cross-price elasticities $\left(e_{G H}{ }^{\prime} s\right)$ in response to a change in the $H^{\text {th }}$ price, with each weight expressed as the share of each food group's contribution to the $k^{\text {th }}$ nutrient $\left(a_{k G} Q_{G} / \psi_{k}^{\prime} s\right)$. Similarly, $\rho_{k}$ represents the weighted average of all income elasticities $\left(e_{G}{ }^{\prime} s\right)$, with each weight expressed as the share of each food's contribution to the $k^{\text {th }}$ nutrient. The matrix of nutrient elasticities is thus obtained as the product of nutrient shares of food groups $S$, and food demand elasticities:

$N=S \times E$. 
